\title{
BMJ Open High prevalence of underweight and undernutrition in Japanese inpatients with schizophrenia: a nationwide survey
}

Takuro Sugai, ${ }^{1,2}$ Yutaro Suzuki, ${ }^{1,2}$ Manabu Yamazaki, ${ }^{3}$ Kazutaka Shimoda, ${ }^{2,4}$ Takao Mori, ${ }^{3}$ Yuji Ozeki, ${ }^{2,4}$ Hiroshi Matsuda, ${ }^{3}$ Norio Sugawara, ${ }^{2,5}$ Norio Yasui-Furukori, ${ }^{2,5}$ Yoshitake Minami, ${ }^{3}$ Kurefu Okamoto, ${ }^{3}$ Toyoaki Sagae, ${ }^{6}$ Toshiyuki Someya ${ }^{1,2}$

To cite: Sugai T, Suzuki Y, Yamazaki M, et al. High prevalence of underweight and undernutrition in Japanese inpatients with schizophrenia: a nationwide survey. BMJ Open 2015;5: e008720. doi:10.1136/ bmjopen-2015-008720

- Prepublication history for this paper is available online. To view these files please visit the journal online (http://dx.doi.org/10.1136/ bmjopen-2015-008720).

Received 12 May 2015 Revised 24 October 2015 Accepted 26 October 2015

CrossMark

For numbered affiliations see end of article.

Correspondence to Professor Toshiyuki Someya; psy@med.niigata-u.ac.jp

\section{ABSTRACT}

Objectives: To clarify the prevalence of underweight and overweight/obesity, and laboratory data for nutritional status in Japanese outpatients and inpatients with schizophrenia.

Design: Cross-sectional study.

Setting: A questionnaire conducted in inpatient and outpatient facilities in Japan.

Participants: The population of adult patients with schizophrenia in Japan ( $\mathrm{N}=23$ 116).

Main outcome measures: The prevalence of underweight and undernutrition in Japanese inpatients and outpatients with schizophrenia.

Results: We conducted a large-scale investigation of the prevalence of underweight and undernutrition in 520 outpatient facilities and 247 inpatient facilities belonging to the Japan Psychiatric Hospitals Association between January 2012 and July 2013. There were 7655 outpatients and 15461 inpatients with schizophrenia. There was a significant difference in the distribution of three body mass index levels between outpatients and inpatients $(p<0.001)$. The proportion of underweight inpatients with schizophrenia was significantly higher than that among outpatients $(p<0.001)$. Age-specific analysis revealed that the proportion of underweight individuals aged $\geq 40$ years was higher in inpatients than in outpatients and in the general Japanese population. The proportion of individuals with hypocholesterolaemia was significantly higher in inpatients with schizophrenia than in outpatients $(p<0.001)$. There was a significant difference in the severity of underweight between outpatients and inpatients with schizophrenia; the proportion of severe underweight in inpatients was twofold higher than in outpatients.

Conclusions: The prevalence of underweight and undernutrition in Japanese inpatients with schizophrenia was higher than in outpatients and the general population. Therefore, the physical risk of inpatients should be carefully considered in clinical practice.

\section{Strengths and limitations of this study}

- Our study is the largest survey clarifying the physical risk of underweight and undernutrition in Japanese patients with schizophrenia.

- A key strength of this study is that the survey was conducted in cooperation with the Japan Psychiatric Hospitals Association, and the majority of Japanese patients with schizophrenia are treated in affiliated facilities.

- The results suggest that the difference in physical health between outpatients and inpatients with schizophrenia may be related to the mental health system in Japan.

- A possible limitation is that the present study used a cross-sectional survey of patients with schizophrenia; therefore, we could not evaluate chronological changes of weight and nutritional status.

\section{INTRODUCTION}

Excess mortality has been reported in patients with schizophrenia compared with the general population. ${ }^{1}$ The life expectancy of people with schizophrenia is approximately 20 years less than that of the general population, and this mortality gap has widened. $^{2}$ Many studies conducted in Europe and North America have shown that patients with schizophrenia treated with antipsychotic agents have a higher prevalence of obesity and metabolic syndrome, which are risk factors for arteriosclerotic disease, compared with healthy individuals. ${ }^{3} 4$ However, Asian populations are generally thinner than their North American and European counterparts. $^{5} 6$ Recently, several studies have reported that being underweight is a recognised health risk, ${ }^{7}$ and some studies have reported increased mortality with weight 
loss. ${ }^{9}{ }^{10}$ We previously showed that the prevalence of underweight and undernutrition in Japanese inpatients with schizophrenia may be higher compared with that in the general population. ${ }^{11}$ Therefore, Japanese inpatients with schizophrenia may have higher mortality risk due to underweight compared with the general population.

In Japan, most psychiatric care is entrusted to private psychiatric hospitals, most of which belong to the Japan Psychiatric Hospitals Association. The mean duration of hospitalisation for patients with schizophrenia in Japan is longer than in Europe and North America. ${ }^{12}$ In total, $66.7 \%$ of all inpatients in psychiatric hospitals in Japan had been hospitalised for $>1$ year at the time of investigation, and patients with schizophrenia or delusional disorders accounted for $59.1 \%$ of all inpatients. ${ }^{12}$ Therefore, differences in healthcare systems between Japan and other countries might affect the nutritional status of patients with schizophrenia. Considering these differences, it is important to examine the prevalence of underweight and overweight/obesity in Japanese patients with schizophrenia. To date, there have only been small-scale studies that have examined these problems in Japan.

In the present study, we used a large-scale survey to establish the prevalence of underweight, and laboratory data of the nutritional status of Japanese inpatients with schizophrenia.

\section{METHODS}

The Japan Psychiatric Hospitals Association comprises 1217 facilities. In a 2008 investigation conducted by the Ministry of Health, Labour and Welfare, the number of Japanese patients with schizophrenia was $795000,{ }^{13}$ with the majority treated in facilities belonging to the Japan Psychiatric Hospitals Association. A joint project with the cooperation of the Japan Psychiatric Hospitals Association and the Japanese Society of Clinical Neuropsychopharmacology, with the aim of protecting patients with schizophrenia, was started in Japan in December 2012.

\section{Study participants}

The questionnaire for the present study was conducted between January 2012 and July 2014. We obtained responses from 7655 outpatients and 15461 inpatients, in 520 outpatient and 247 inpatient facilities belonging to the Japan Psychiatric Hospitals Association. All patients had been diagnosed with schizophrenia based on the Diagnostic and Statistical Manual of Mental Disorders, fourth edition, text revision, or the International Statistical Classification of Diseases and Related Health Problems, Tenth Revision. We excluded individuals aged $<20$ years and those whose sex and body mass index (BMI) data were not assessed $(n=3438)$. A total of 19678 individuals (5441 outpatients and 14237 inpatients) were included in the final analysis (figure 1). All participants provided verbal informed consent to participate in the study, without any incentive. The anonymous questionnaire was the only research instrument, and included the following statement, 'The completion of the attached questionnaire will be taken as indicating your consent to participate'. The questionnaire was completed by participants themselves.

\section{Measurements}

A brief questionnaire was compiled to cover demographic data (age and sex), body height and weight, waist circumference (WC), total cholesterol (TC), triglyceride (TG), high-density lipoprotein (HDL) cholesterol and fasting plasma glucose (FPG) levels, based on a review of relevant literature and guidelines. BMI was determined as the ratio of weight to height $\left(\mathrm{kg} / \mathrm{m}^{2}\right)$. Questions from standardised health questionnaires were used to determine behaviour, including current smoking status. TC, TG and FPG were measured using standard analytical techniques. The chlorpromazine (CP) equivalent was also calculated by standardised methods. ${ }^{14}$

Undernutritional status, such as hypocholesterolaemia, hypotriglyceridaemia and hypoglycaemia, was defined as having TC $<150 \mathrm{mg} / \mathrm{dL}, \mathrm{TG}<50 \mathrm{mg} / \mathrm{dL}$ and $\mathrm{FPG}<70 \mathrm{mg} /$ $\mathrm{dL}$, respectively. Overweight was defined as $\mathrm{BMI} \geq 25$ to $<30 \mathrm{~kg} / \mathrm{m}^{2}$, obesity as $\mathrm{BMI} \geq 30 \mathrm{~kg} / \mathrm{m}^{2}$ and underweight as $\mathrm{BMI}<18.5 \mathrm{~kg} / \mathrm{m}^{2}$. Underweight participants were divided into two subcategories: mild underweight (17$\left.18.49 \mathrm{~kg} / \mathrm{m}^{2}\right)$ and moderate-severe underweight $\left(<16.99 \mathrm{~kg} / \mathrm{m}^{2}\right) .{ }^{1516}$

\section{Statistical analysis}

Clinical and demographic characteristics were compared between outpatients and inpatients with schizophrenia, and between underweight, standard weight, overweight and obesity categories, using $\chi^{2}$ tests and unpaired $\mathrm{t}$ tests. A multivariate logistic regression analysis was performed to assess the association of daily smoking on BMI, and type and dose of antipsychotic medication. The threshold for significance was set at $\mathrm{p}<0.05$. We used SPSS V.19.0 (IBM Japan, Tokyo, Japan) for the statistical analyses.

\section{RESULTS}

\section{Demographic and clinical characteristics}

Table 1 shows the difference in demographic and clinical characteristics between outpatients and inpatients by sex. Compared with outpatients, inpatients were significantly older and had lower BMI, WC, systolic blood pressure, diastolic blood pressure, low-density lipoprotein, TC, TG and FPG levels. These results were similar for both sexes. In the overall analysis, there was no difference in HDL levels between outpatients and inpatients, although female outpatients had significantly higher HDL than female inpatients. Outpatients had a significantly higher prevalence of lifestyle-related diseases such as hypertension, lipid abnormalities and diabetes mellitus than did inpatients. There was a significant 
Figure 1 Flow diagram of participant inclusion and exclusion (BMI, body mass index).
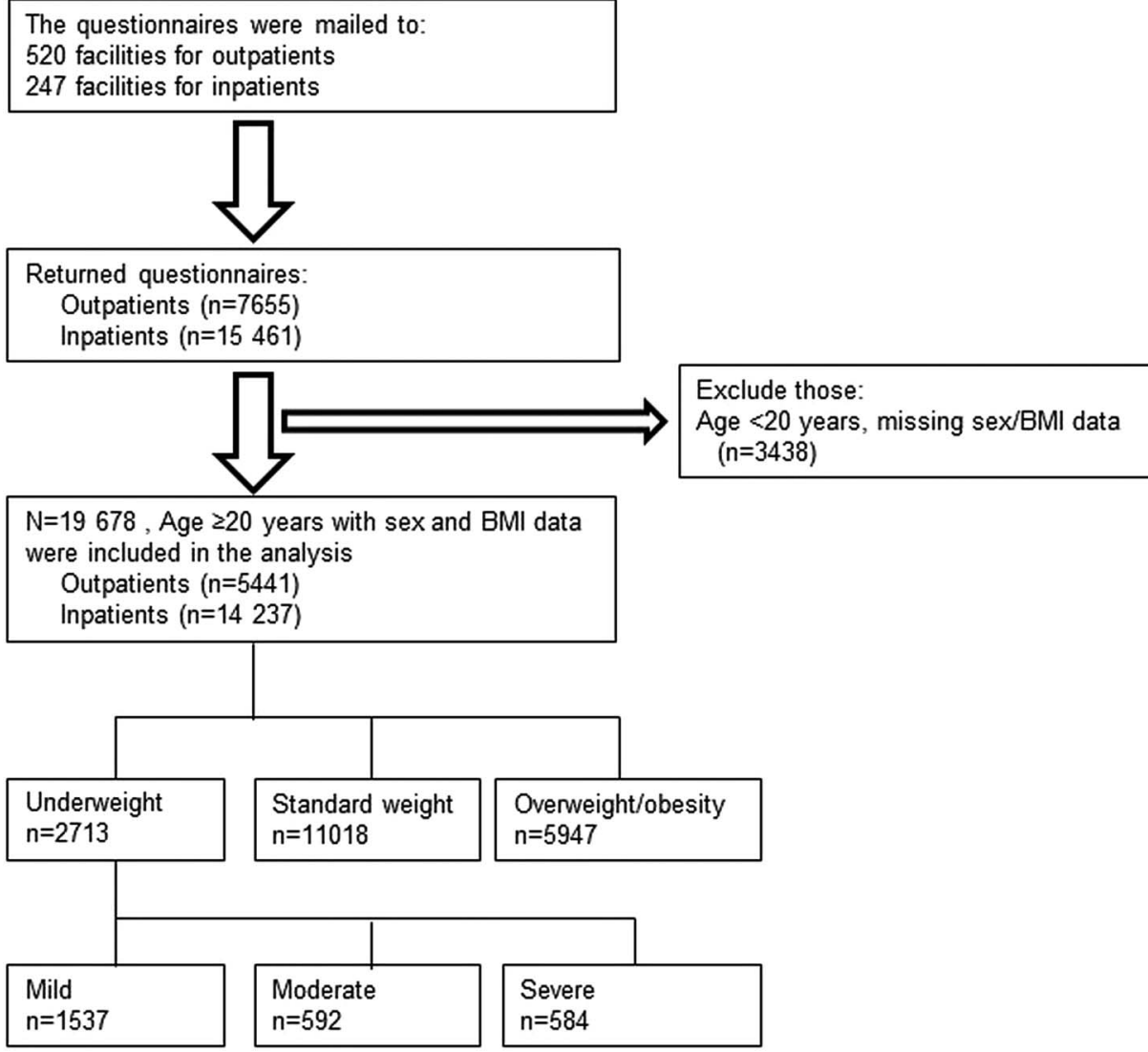

difference in antipsychotic therapy status between outpatients and inpatients. Total CP equivalence was higher in inpatients than in outpatients. Smoking was more common in outpatients than in inpatients. The proportion of current smokers, hypertension and diabetes mellitus in the general Japanese population is 20.1\%, 27.2\% and $10.9 \%$, respectively. ${ }^{17} \mathrm{~A}$ multivariate logistic regression analysis showed that daily smoking had no significant association on BMI or type and dose of antipsychotic medication.

\section{Age-specific underweight in outpatients and inpatients} compared with the general population

Table 2 shows the proportions of underweight individuals among outpatients, inpatients and the general Japanese population, by age. ${ }^{17}$ Overall, the proportion of underweight inpatients $(17.4 \%)$ was significantly higher than that among outpatients $(4.3 \%)$ and the general population $(7.9 \%)$. In particular, these differences were marked in individuals aged $\geq 40$ years. For those aged $\geq 60$ years, the proportion of underweight inpatients was approximately threefold higher than that among outpatients and the general population. In male patients aged $\geq 50$ years, the proportion of underweight inpatients was 4-6 folds higher than that in outpatients.

\section{Demographic data and nutritional status according to BMI}

Table 3 shows the comparison of demographic data and nutritional status between outpatients and inpatients across four BMI categories. The proportion of inpatients with moderate-severe underweight was 5.6-fold higher than that of outpatients $(1102 / 15461(7.1 \%)$ vs $74 / 5441$ $(1.4 \%))$. For all BMI categories, the proportion of inpatients with hypocholesterolaemia was 2-3 folds higher than that of outpatients. As BMI decreased, the difference in the prevalence of undernutrition between outpatients and inpatients widened. The proportion of inpatients with hypoglycaemia was 2.7-fold higher in the standard weight group, 4.0-fold higher in the overweight group and 15.2-fold higher in the overweight/obesity group.

\section{DISCUSSION}

In the present study, we revealed that the prevalence of underweight and undernutrition in Japanese inpatients with schizophrenia was higher compared with outpatients and the general population. Moreover, a higher proportion of severe-moderate underweight was observed in inpatients with schizophrenia compared with that in outpatients (table 3). To the best of our knowledge, the present study is the largest survey clarifying the physical risk of underweight and undernutrition in Japanese inpatients with schizophrenia.

Table 3 suggested that the total number of Japanese patients with schizophrenia had higher prevalence of underweight (moderate-severe + mild) and overweight/ obesity compared with the general Japanese population (table 3: underweight $13.8 \%$ vs $7.9 \%{ }^{17}$; overweight/ obesity: $30.2 \%$ vs $24.7 \%^{17}$ ). In particular, inpatients had 
Table 1 Difference in demographic and clinical characteristics between outpatients and inpatients

\begin{tabular}{|c|c|c|c|c|c|c|c|c|c|}
\hline & \multicolumn{3}{|l|}{ Total } & \multicolumn{3}{|l|}{ Male } & \multicolumn{3}{|l|}{ Female } \\
\hline & $\begin{array}{l}\text { Outpatients } \\
(n=5441)\end{array}$ & $\begin{array}{l}\text { Inpatients } \\
(n=14237)\end{array}$ & p Value & $\begin{array}{l}\text { Outpatients } \\
(n=3147)\end{array}$ & $\begin{array}{l}\text { Inpatients } \\
(\mathrm{n}=7527)\end{array}$ & p Value & $\begin{array}{l}\text { Outpatients } \\
(n=2294)\end{array}$ & $\begin{array}{l}\text { Inpatients } \\
(n=6710)\end{array}$ & p Value \\
\hline Age (years) & $52.2 \pm 13.7$ & $60.0 \pm 12.9$ & $<0.001^{*}$ & $51.8 \pm 13.0$ & $58.7 \pm 12.7$ & $<0.001^{*}$ & $52.9 \pm 14.4$ & $61.5 \pm 13.0$ & $<0.001^{\star}$ \\
\hline BMI $\left(\mathrm{kg} / \mathrm{m}^{2}\right)$ & $25.3 \pm 4.6$ & $22.3 \pm 4.0$ & $<0.001^{*}$ & $25.4 \pm 4.2$ & $22.2 \pm 3.7$ & $<0.001^{*}$ & $25.3 \pm 5.0$ & $22.4 \pm 4.3$ & $<0.001^{*}$ \\
\hline WC $(\mathrm{cm})$ & $87.6 \pm 12.8$ & $83.4 \pm 11.5$ & $<0.001^{*}$ & $90.2 \pm 11.4$ & $84.8 \pm 10.7$ & $<0.001^{*}$ & $83.9 \pm 13.8$ & $81.8 \pm 12.2$ & $<0.001^{*}$ \\
\hline Systolic blood pressure (mm Hg) & $127.2 \pm 18.2$ & $120.4 \pm 17.2$ & $<0.001^{*}$ & $128.9 \pm 17.7$ & $121.3 \pm 17.1$ & $<0.001^{*}$ & $124.8 \pm 18.6$ & $119.4 \pm 17.3$ & $<0.001^{\star}$ \\
\hline Diastolic blood pressure $(\mathrm{mm} \mathrm{Hg})$ & $78.2 \pm 12.4$ & $74.5 \pm 12.1$ & $<0.001^{*}$ & $79.5 \pm 12.2$ & $75.4 \pm 12.0$ & $<0.001^{*}$ & $76.4 \pm 12.4$ & $73.4 \pm 12.2$ & $<0.001^{*}$ \\
\hline HDL cholesterol (mg/dL) & $55.9 \pm 19.0$ & $55.0 \pm 19.9$ & $\mathrm{NS}^{*}$ & $51.4 \pm 16.3$ & $50.9 \pm 18.8$ & $\mathrm{NS}^{*}$ & $62.0 \pm 20.6$ & $59.6 \pm 20.0$ & $0.002^{*}$ \\
\hline LDL cholesterol (mg/dL) & $117.6 \pm 34.9$ & $106.9 \pm 44.8$ & $<0.001^{*}$ & $117.1 \pm 35.4$ & $101.9 \pm 39.1$ & $<0.001^{*}$ & $118.3 \pm 34.2$ & $112.5 \pm 49.7$ & $0.001^{*}$ \\
\hline $\mathrm{TC}(\mathrm{mg} / \mathrm{dL})$ & $196.7 \pm 38.4$ & $177.7 \pm 37.1$ & $<0.001^{*}$ & $192.6 \pm 38.4$ & $168.3 \pm 34.1$ & $<0.001^{*}$ & $202.1 \pm 37.7$ & $188.5 \pm 37.4$ & $<0.001^{*}$ \\
\hline $\mathrm{TG}(\mathrm{mg} / \mathrm{dL})$ & $141.9 \pm 99.4$ & $101.0 \pm 58.7$ & $<0.001^{*}$ & $153.8 \pm 109.0$ & $102.8 \pm 62.2$ & $<0.001^{*}$ & $125.8 \pm 82.1$ & $99.0 \pm 54.5$ & $<0.001^{*}$ \\
\hline $\mathrm{FPG}(\mathrm{mg} / \mathrm{dL})$ & $108.4 \pm 40.3$ & $92.6 \pm 24.4$ & $<0.001^{*}$ & $110.6 \pm 42.1$ & $92.8 \pm 22.8$ & $<0.001^{*}$ & $105.5 \pm 37.6$ & $92.4 \pm 26.1$ & $<0.001^{*}$ \\
\hline $\mathrm{Na}(\mathrm{mEq} / \mathrm{L})$ & - & $140.1 \pm 4.4$ & - & - & $139.6 \pm 4.8$ & - & - & $140.8 \pm 3.9$ & - \\
\hline $\mathrm{K}(\mathrm{mEq} / \mathrm{L})$ & - & $4.2 \pm 0.5$ & - & - & $4.2 \pm 0.5$ & - & - & $4.2 \pm 0.5$ & - \\
\hline \multicolumn{10}{|l|}{ Lifestyle-related diseases } \\
\hline Prevalence of hypertension (\%) & 30.5 & 19.9 & $<0.001 \dagger$ & 34.0 & 21.2 & $<0.001 \dagger$ & 25.6 & 18.5 & $<0.001 \dagger$ \\
\hline Prevalence of lipid abnormality (\%) & 46.6 & 27.8 & $<0.001 \dagger$ & 48.5 & 26.7 & $<0.001 \dagger$ & 43.9 & 29.0 & $<0.001 \dagger$ \\
\hline Prevalence of diabetes mellitus (\%) & 16.8 & 7.1 & $<0.001 \dagger$ & 18.3 & 7.3 & $<0.001 \dagger$ & 14.7 & 6.9 & $<0.001 \dagger$ \\
\hline \multicolumn{10}{|l|}{ Status of antipsychotic therapy } \\
\hline No treated $(\%)$ & 6.2 & 7.3 & $<0.001 \dagger$ & 5.9 & 7.1 & $<0.001 \dagger$ & 6.6 & 7.6 & $<0.001 \dagger$ \\
\hline Antipsychotic monopharmacy (\%) & 49.4 & 40.3 & & 46.9 & 38.3 & & 52.8 & 42.6 & \\
\hline Antipsychotic polypharmacy (\%) & 44.4 & 52.4 & & 47.2 & 54.7 & & 40.6 & 49.8 & \\
\hline Ratio of SGA therapy (\%) & 73.3 & 75.8 & $<0.001 \dagger$ & 72.8 & 74.8 & $0.03+$ & 74.0 & 76.8 & $0.005 \dagger$ \\
\hline Total CP equivalence (mg) & $532.0 \pm 472.6$ & $691.1 \pm 622.3$ & $<0.001^{*}$ & $556.9 \pm 474.5$ & $723.1 \pm 650.9$ & $<0.001^{*}$ & $497.9 \pm 468.0$ & $655.2 \pm 586.5$ & $<0.001^{\star}$ \\
\hline Smoking (\%) & 36.2 & 24.0 & $<0.001 \dagger$ & 47.8 & 36.0 & $<0.001 \dagger$ & 20.3 & 10.4 & $<0.001 \dagger$ \\
\hline
\end{tabular}

Data are expressed as mean \pm SD

Hypertension was defined as systolic blood pressure $\geq 130 \mathrm{~mm} \mathrm{Hg}$ and/or diastolic blood pressure $\geq 85 \mathrm{~mm} \mathrm{Hg}$.

Lipid abnormality was defined as $\mathrm{HDL}<40 \mathrm{mg} / \mathrm{dL}$ in males and $<50 \mathrm{mg} / \mathrm{dL}$ in females, and/or LDL $\geq 140 \mathrm{mg} / \mathrm{dL}, \mathrm{TC} \geq 220 \mathrm{mg} / \mathrm{dL}$ and TG $\geq 150 \mathrm{mg} / \mathrm{dL}$

Diabetes mellitus was defined as $\mathrm{FPG} \geq 126 \mathrm{mg} / \mathrm{dL}$.

*Data are analysed using unpaired Student $t$ test between outpatients and inpatients.

†Data are analysed using $\chi 2$ test between outpatients and inpatients.

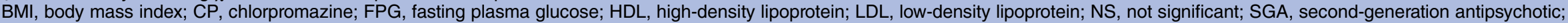
TC, total cholesterol; TG, triglyceride; WC, waist circumference. 


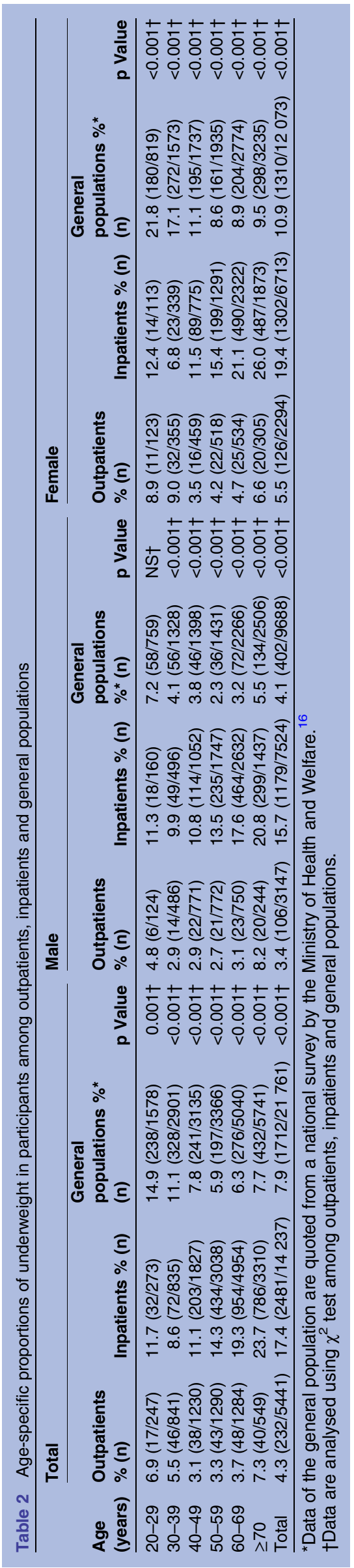

higher prevalence of underweight than did outpatients. Previously, we also reported that Japanese inpatients had higher prevalence of underweight compared with the general Japanese population although there was no difference in the prevalence of overweight/obesity. ${ }^{11}$ A previous study reported that the proportion of Japanese inpatients with schizophrenia who were underweight was $16.1 \%,{ }^{18}$ while another study found that the proportion of Japanese inpatients with schizophrenia who were underweight was $20.2 \% .^{19}$ These results were similar in that there was a high prevalence of underweight in Japanese inpatients with schizophrenia. Our results are consistent with these two previous studies. However, we could not establish why there is a high prevalence of underweight inpatients with schizophrenia in Japan. A possible reason may be that long-term hospitalisation has a detrimental effect on the physical health of patients with schizophrenia. The mental health system in Japan is still hospital based, and has the largest number of psychiatric beds per person in the world. In Japan, the average length of hospital stay is 8.5 years, with $71 \%$ of psychiatric inpatients remaining in hospital for $\geq 1$ year. ${ }^{20}$ Long-term hospitalisation leads to lack of exercise, which is a factor that may cause a decline in bone density. ${ }^{21}$ Being underweight has also been reported to be related to low bone density. ${ }^{22}$ Therefore, factors associated with long-term hospitalisation may affect weight loss in patients with schizophrenia. Second, because most patients with schizophrenia who have been hospitalised long-term have severe psychotic symptoms, such as negative symptoms, cognitive impairment and social isolation, and are refractory, they may not seek help for symptoms of physical illness. ${ }^{23}$ Therefore, a physical illness causing weight loss may be easily overlooked in patients with schizophrenia who have been hospitalised long term.

The effect of being underweight on mortality has also been reported in the general population. A previous study reported that both a lower BMI and a higher BMI increased the HR for all-cause mortality. ${ }^{24}$ Another study conducted with East and South Asians showed an elevated risk of death from cardiovascular disease at lower BMI. ${ }^{25}$ In the present study, the proportion of inpatients who were underweight increased with age, compared with outpatients and the general population (table 2). As underweight is a significant predictor of mortality, ${ }^{26}$ being more severely underweight may lead to excess mortality in older inpatients with schizophrenia.

A higher prevalence of hypocholesterolaemia and hypoglycaemia was observed in inpatients with schizophrenia compared with outpatients (table 3). Our previous study also showed that the prevalence of hypocholesterolaemia and hypotriglyceridaemia were significantly higher in patients with schizophrenia than in healthy subjects. ${ }^{11}$ These findings may be partly explained by these conditions having resulted in underweight in inpatients with schizophrenia. In general, blood cholesterol levels tend to decrease as age 
increases. ${ }^{27}$ In the present study, inpatients were significantly older than outpatients. Although we could not clearly clarify whether a low cholesterol level in older adults was a marker for fragility, undernutrition or subclinical diseases, one possible reason is that various causes, such as weight loss, low serum albumin and reduced functional ability, may be involved with low cholesterol levels in older adults. Conversely, a lower prevalence of hypertension and diabetes mellitus was observed in inpatients with schizophrenia compared with outpatients and the general Japanese population. Other studies have also established a lower prevalence of hypertension and diabetes mellitus in inpatients than that in outpatients. ${ }^{28-30}$ We were unable to establish why Japanese inpatients with schizophrenia had a lower prevalence of hypertension and diabetes mellitus. However, a possible reason is that inpatients receive constant lifestyle management. Moreover, outpatients and inpatients had higher proportion of current smokers than the general Japanese population in the present study. The association between smoking and schizophrenia is strong and widely replicated. ${ }^{31}$ Our result did not contradict those previous studies. We should be careful about the relationship between lifestyle diseases and smoking habits. It was also noteworthy that there were patients in the standard and overweight/obesity categories with undernutrition. Long-term hospitalisation and antipsychotic therapy decrease gastrointestinal motility, ${ }^{32}$ and may lead to undernutrition in patients with standard weight and overweight/obesity. Therefore, we must direct attention to the problem of undernutrition as well as to underweight.

There were several limitations in the present study. First, because the present study was a cross-sectional survey of patients with schizophrenia, we could not evaluate chronological changes of weight and nutritional status. Second, because no information about the duration of illness and medication was available, we could not evaluate the effect of these factors on BMI. Third, eating behaviour and amount of exercise were not investigated in sufficient detail, and we could not examine the effect of these factors on BMI. Fourth, in terms of reporting the response rate, we mailed the questionnaire to the facilities that consented to participate in the investigation. However, as we did not obtain information about the number of patients who refused to participate in the investigation from all facilities, we could not report details about the overall response rate. Fifth, in the present study, we did not include other biochemical parameters, such as protein and micronutrients, which are typically used in clinical practice to indicate undernutritional status. Because it was supposed that blood protein density correlates with body weight, ${ }^{33}$ we regarded body weight as one of the most important risk factors of undernutrition. Therefore, future studies are needed to investigate these biochemical parameters as indicators for undernutritional status in patients with schizophrenia.

\section{CONCLUSIONS}

We conducted a large-scale survey, and observed that Japanese inpatients with schizophrenia were more likely to be underweight and have undernutrition than outpatients. Japan has the longest average length of hospitalisation in the world, and there has been a gradual ageing of inpatients. These aspects of the mental health system in Japan may be related to the differences in physical health between outpatients and inpatients with schizophrenia. Our findings suggest that the physical health of inpatients should be more carefully considered in clinical practice.

\section{Author affiliations}

${ }^{1}$ Department of Psychiatry, Niigata University Graduate School of Medical and Dental Sciences, Niigata, Japan

2Japanese Society of Clinical Neuropsychopharmacology, Tokyo, Japan

${ }^{3}$ Japan Psychiatric Hospital Association, Tokyo, Japan

${ }^{4}$ Department of Psychiatry, Dokkyo Medical University School of Medicine, Mibu, Japan

${ }^{5}$ Department of Neuropsychiatry, Hirosaki University School of Medicine, Hirosaki, Japan

${ }^{6}$ Faculty of Health and Nutrition, Department of Health and Nutrition, Yamagata Prefectural Yonezawa University of Nutrition Sciences, Yonezawa, Japan

Acknowledgements The authors would like to acknowledge the study participants and the facilities belonging to the Japan Psychiatric Hospitals Association that cooperated with the present investigation. They would also like to thank all of our coworkers for their contributions to the data collection and management. They also thank Yuichiro Watanabe and Naoki Fukui for critical comments on the manuscript.

Contributors TSu is the main contributor to the design of the present study. TSu, YS, KS, YO, NS, NY-F and TSo contributed to the study conception and design. MY, TM, HM, YM, KO and TSa were involved in the acquisition of data. TSu and YS contributed to the drafting of the manuscript. KS, YO, NS, NY-F and TSo were involved in the critical revision. All the authors were involved in the analysis and interpretation of the data and gave their final approval.

Funding This work was partially supported by Eisai Co, Ltd; Yoshitomi Pharmaceutical Industries; Dainippon Sumitomo Pharma Co, Ltd; Astellas Pharma Inc; Meiji Seika Pharma Co, Ltd; Eli Lilly Japan, KK; Otsuka Pharmaceutical Co, Ltd; GlaxoSmithKline KK; Janssen Pharmaceutical KK; MSD KK; Shionogi \& Co, Ltd; Asahi Kasei Pharma Corp; Novartis Pharma Co, Ltd; Takeda Pharmaceutical Co, Ltd; Ono Pharmaceutical Co, Ltd; and Tsumura \& Co.

Competing interests ToS has received research support or honoraria from Asahi Kasei Pharma Corp; Astellas Pharma Inc; Daiichi Sankyo Co, Ltd; Dainippon Sumitomo Pharma Co, Ltd; Eisai Co, Ltd; Eli Lilly Japan, KK; GlaxoSmithKline KK; Janssen Pharmaceutical KK; Meiji Seika Pharma Co, Ltd; Mitsubishi Tanabe Pharma Co, Ltd; Mochida Pharmaceutical Co, Ltd; MSD KK; Otsuka Pharmaceutical Co, Ltd; Pfizer Japan Inc; Shionogi \& Co, Ltd; Tsumura \& $\mathrm{Co}$ and Yoshitomi Pharmaceutical Industries. YS has received research support or honoraria from Janssen Pharmaceutical KK; Mitsubishi Tanabe Pharma Co, Ltd and Otsuka Pharmaceutical Co, Ltd. KS has received research support or honoraria from Daiichi Sankyo Co, Ltd; Dainippon Sumitomo Pharma Co, Ltd; Eisai Co, Ltd; Eli Lilly Japan, KK; GlaxoSmithKline KK; Meiji Seika Pharma Co, Ltd; Novartis Pharma KK; Otsuka Pharmaceutical Co, Ltd; Pfizer Japan Inc; Shionogi \& Co, Ltd; Takeda Pharmaceutical Co, Ltd; Tsumra \& Co; Yoshitomi Pharmaceutical Industries, Ltd; Asahi Kasei Pharma Corporation; Astellas Pharma Inc; Janssen Pharmaceutical KK; Kowa Pharmaceutical Co, Ltd; Meiji Seika Pharma Co; Mitsubishi Tanabe Pharma Corporation, Ltd; MSD KK and Ono Pharmaceutical Co, Ltd. NY-F has received research support or honoraria from Astellas Pharma Inc; Dainippon Sumitomo Pharma Co, Ltd; Eli Lilly Japan, KK; GlaxoSmithKline KK; Janssen 
Pharmaceutical KK; Meiji Seika Pharma Co; Mochida Pharmaceutical Co, Ltd; MSD KK; Otsuka Pharmaceutical Co, Ltd; Pfizer Japan Inc; Takeda Pharmaceutical Co, Ltd and Yoshitomi Pharmaceutical Industries. NS has received grant/research support from a Grant-in-Aid for Young Scientists (B); The Ministry of Education, Culture, Sports, Science and Technology, Japan Grant B; Karoji Memorial Fund for Medical Research Grant and SENSHIN Medical Research Foundation.

Ethics approval The study was approved by the Ethics Committee of the Japan Psychiatric Hospitals Association.

Provenance and peer review Not commissioned; externally peer reviewed.

Data sharing statement No additional data are available.

Open Access This is an Open Access article distributed in accordance with the Creative Commons Attribution Non Commercial (CC BY-NC 4.0) license, which permits others to distribute, remix, adapt, build upon this work noncommercially, and license their derivative works on different terms, provided the original work is properly cited and the use is non-commercial. See: http:// creativecommons.org/licenses/by-nc/4.0/

\section{REFERENCES}

1. Nordentoft M, Wahlbeck K, Hallgren J, et al. Excess mortality, causes of death and life expectancy in 270,770 patients with recent onset of mental disorders in Denmark, Finland and Sweden. PLoS ONE 2013;8:e55176

2. Saha S, Chant D, McGrath J. A systematic review of mortality in schizophrenia: is the differential mortality gap worsening over time? Arch Gen Psychiatry 2007;64:1123-31.

3. Casey DE. Metabolic issues and cardiovascular disease in patients with psychiatric disorders. Am J Med 2005;118(Suppl 2): 15S-22S.

4. Gurpegui M, Martínez-Ortega JM, Gutiérrez-Rojas L, et al. Overweight and obesity in patients with bipolar disorder or schizophrenia compared with a non-psychiatric sample. Prog Neuropsychopharmacol Biol Psychiatry 2012;37:169-75.

5. WHO Expert Consultation. Appropriate body-mass index for Asian populations and its implications for policy and intervention strategies. Lancet 2004;363:157-63.

6. Goh VH, Tain CF, Tong TY, et al. Are BMl and other anthropometric measures appropriate as indices for obesity? A study in an Asian population. J Lipid Res 2004;45:1892-8.

7. Janssen I, Mark AE. Elevated body mass index and mortality risk in the elderly. Obes Rev 2007;8:41-59.

8. Flegal KM, Graubard BI, Williamson DF, et al. Reverse causation and illness-related weight loss in observational studies of body weight and mortality. Am J Epidemiol 2011;173:1-9.

9. Droyvold WB, Lund Nilsen TI, Lydersen S, et al. Weight change and mortality: the nord-trondelag health study. J Intern Med 2005;257:338-45

10. Wirth R, Streicher M, Smoliner C, et al. The impact of weight loss and low BMI on mortality of nursing home residents-results from the nutritionDay in nursing homes. Clin Nutr 2015.

11. Suzuki $Y$, Sugai T, Fukui N, et al. High prevalence of underweight and undernutrition in Japanese inpatients with schizophrenia. Psychiatry Clin Neurosci 2014;68:78-82.

12. Ministry of Health, Labour and Welfare. Patient Survey. 2009. http:// www.ncnp.go.jp/nimh/keikaku/vision/630data.htm/
13. Ministry of Health, Labour and Welfare. Patient Survey. 2008. http:// www.ncnp.go.jp/nimh/keikaku/vision/630data.html

14. Woods SW. Chlorpromazine equivalent doses for the newer atypical antipsychotics. J Clin Psychiatry 2003;64:663-7.

15. James WP, Chunming $\mathrm{C}$, Inoue $\mathrm{S}$. Appropriate Asian body mass indices? Obes Rev 2002;3:139.

16. Misra A. Redefining obesity in Asians: more definitive action is required from the WHO. Natl Med J India 2004;17:1-4.

17. Ministry of Health, Labour and Welfare. National Health and Nutrition Examination Survey. 2012. http://www.mhlw.go.jp/bunya/kenkou/ eiyou/h22-houkoku.html

18. Kitabayashi $\mathrm{Y}$, Narumoto J, Kitabayashi M, et al. Body mass index among Japanese inpatients with schizophrenia. Int J Psychiatry Med 2006;36:93-102.

19. Inamura $Y$, Sagae T, Nakamachi K, et al. Body mass index of inpatients with schizophrenia in Japan. Int $J$ Psychiatry Med 2012;44:171-81.

20. Ministry of Health and Welfare. Patient Survey 1996. Tokyo: Statistics and Information Department, Minister's Secretariat, Ministry of Health and Welfare, 1999.

21. Carter MI, Hinton PS. Physical activity and bone health. Mo Med 2014;111:59-64.

22. Pines $A$. Weight loss, weight regain and bone health. Climacteric 2012;15:317-19.

23. De Hert M, Cohen D, Bobes J, et al. Physical illness in patients with severe mental disorders. II. Barriers to care, monitoring and treatment guidelines, plus recommendations at the system and individual level. World Psychiatry 2011;10:138-51.

24. Hong S, Yi SW, Sull JW, et al. Body mass index and mortality among Korean elderly in rural communities: Kangwha Cohort Study. PLOS ONE 2015;10:e0117731.

25. Chen $\mathrm{Y}$, Copeland WK, Vedanthan R, et al. Association between body mass index and cardiovascular disease mortality in east Asians and south Asians: pooled analysis of prospective data from the Asia Cohort Consortium. BMJ 2013;347:f5446.

26. Wu CY, Chou YC, Huang N, et al. Association of body mass index with all-cause and cardiovascular disease mortality in the elderly. PLOS ONE 2014;9:e102589.

27. Chu NF, Ding YA, Wang DJ, et al. Relationship between smoking status and cardiovascular disease risk factors in young adult males in Taiwan. J Cardiovasc Risk 1996;3:205-8.

28. Nasrallah HA, Meyer JM, Goff DC et al. Low rates of treatment for hypertension, dyslipidaemia and diabetes in schizophrenia: data from the CATIE schizophrenia trial sample at baseline. Schizophr Res 2006;86:15-22.

29. Osborn DP, Wright CA, Levy G, et al. Relative risk of diabetes, dyslipidaemia, hypertension and the metabolic syndrome in people with severe mental illnesses: systematic review and meta-analysis. BMC Psychiatry 2008;8:84.

30. Bresee LC, Majumdar SR, Patten SB, et al. Prevalence of cardiovascular risk factors and disease in people with schizophrenia: a population-based study. Schizophr Res 2010;117:75-82.

31. de Leon J, Diaz FJ. A meta-analysis of worldwide studies demonstrates an association between schizophrenia and tobacco smoking behaviors. Schizophr Res 2005;76:135-57.

32. Berger S, Hocke M, Bär KJ. Gastric dysmotility in healthy first-degree relatives of patients with schizophrenia. Prog Neuropsychopharmacol Biol Psychiatry 2010;34:1294-9.

33. Ankarfeldt MZ, Angquist L, Jakobsen MU, et al. Interactions of dietary protein and adiposity measures in relation to subsequent changes in body weight and waist circumference. Obesity (Silver Spring) 2014;22:2097-103. 